\title{
ANALISIS PENERAPAN AKUNTANSI LEASING ATAS PEROLEHAN ASET TETAP PADA PT. BANK SULUTGO KANTOR PUSAT
}

\author{
Raynaldi Manginsela ${ }^{1}$, David P.E. Saerang ${ }^{2}$, Heince R.N. Wokas ${ }^{3}$ \\ ${ }^{1,2,3}$ Fakultas Ekonomi dan Bisnis, Jurusan Akuntansi, Universitas Sam Ratulangi, Jl. Kampus Bahu, Manado, \\ 95115, Indonesia
}

E-mail : manginselaraynaldi@gmail.com

\begin{abstract}
Leasing activities are an alternative financing to obtain fixed assets in supporting the operational activities of a company. PT. Bank SulutGo is a company engaged in financial services (banking) that chooses leasing as one of the ways to obtain fixed assets.This study aims to find out how the application of leasing accounting to the acquisition for fixed assets at PT. Bank SulutGo Head Office based on PSAK No. 30. The research method used is qualitative descriptive.The results of the research show that leasing transactions conducted by PT. Bank SulutGo is classified as a finance lease which at the end of the lease period there is a transfer of asset ownership to PT. Bank SulutGo. The application of leasing accounting to the acquisition for fixed assets at PT. Bank SulutGo has not been fully implemented under PSAK No. 30 concerning leasing accounting.
\end{abstract}

Keywords: Accounting for Leases, PSAK No. 30, Fixed Assets

\section{PENDAHULUAN}

Leasing atau sewa merupakan suatu kegiatan pembiayaan dimana lessor (pemilik aset) memberikan hak kepada lessee (penyewa) suatu aset untuk digunakan dalam waktu yang telah disepakati dan sebagai imbalan lessee atau penyewa melakukan pembayaran secara berkala dengan jumlah yang disepakati bersama di awal transaksi, dan pada masa sewa berakhir, penyewa bisa memiliki hak opsi untuk membeli aset tersebut. Sewa guna usaha merupakan salah satu alternatif pembiayaan yang baik bagi perusahaan yang modalnya kurang atau juga melakukan penghematan atas pemakaian suatu aset dan tidak juga dalam sektor ekonomi tertentu kehilangan kesempatan dalam melakukan investasi yang dianggap produktif. Pembiayaan melalui leasing tidak memerlukan prosedur yang rumit, proses yang panjang serta jaminan yang besar. Keringanan ini dikarenakan selama masa leasing status barang tersebut milik perusahaan leasing. Sewa aset tetap adalah komponen utama dalam strategi keuangan bagi banyak perusahaan. Sewa bisa digunakan untuk meminimalkan risiko, meningkatkan arus kas, mengurangi biaya atau memperbaiki laporan keuangan (Bashi dan Molla, 2013).

PT. Bank SulutGo adalah salah satu perusahaan yang bergerak di bidang jasa keuangan yaitu perbankan yang berlokasi di Jl. Sam Ratulangi No. 9 Manado Sulawesi Utara. PT. Bank SulutGo menggunakan Standar Akuntansi Keuangan (SAK) sebagai standar atas laporan keuangan PT. Bank SulutGo. Salah satu aset tetap yang disewagunausahakan oleh PT. Bank SulutGo yaitu mesin ATM. Dalam hal ini PT. Bank SulutGo bertindak sebagai lessee yaitu pihak yang menyewa guna usaha barang modal atau aset tetap dari lessor. Pada PT. Bank SulutGo yang bisa dibelanjakan sebagai capex atau biaya modal sebagai investasi sebesar 30\% dari modal PT. Bank SulutGo. Jika pengeluaran modal sudah mendekati atau sudah mencapai 30\% yang merupakan ketentuan yang ditetapkan oleh PT. Bank SulutGo, maka PT. Bank SulutGo tidak bisa lagi melakukan pengeluaran modal secara tunai, sehingga PT. Bank SulutGo mencari alternatif lain untuk mendapatkan suatu aset tetap yaitu dengan cara leasing atau sewa guna usaha. Hal itu juga merupakan alasan mengapa PT. Bank 
SulutGo melakukan sewa sebagai alternatif untuk memperoleh aset tetap dan bukan membeli secara tunai. Alasan lainnya juga kenapa PT. Bank SulutGo memilih sewa bukan dengan cara membeli sendiri atau pembelian tunai karena melihat kemajuan teknologi yang berkembang pesat PT. Bank SulutGo bisa membatalkan atau menukar aset tetap lama yang disewa dengan aset tetap yang terbaru yang lebih canggih, selain itu PT. Bank SulutGo juga menghindari biaya maintenance atau pemeliharaan dan perbaikan aset tetap yang tinggi yang digunakan untuk kelancaran kegiatan operasional perusahaan. Pada laporan keuangan PT. Bank SulutGo untuk aset sewa guna usaha tidak terlihat dalam neraca yaitu aset sewa guna usaha dan utang sewa guna usaha, sedangkan berdasarkan PSAK No.30 menyatakan bahwa untuk sewa pembiayaan harus dicantumkan ke dalam laporan posisis keuangan yaitu neraca dengan akun aset sewa guna usaha dan utang sewa guna usaha, dikarenakan tidak adanya akun sewa guna usaha yang terdaftar pada sistem PT. Bank SulutGo.

\section{TINJAUAN PUSTAKA}

Akuntansi. Akuntansi merupakan suatu ilmu pengetahuan yang mempunyai peranan penting dalam masalah pengadaan, pencatatan, pengelompokkan, proses analisis, interpretasi, dan penyajian informasi-informasi yang dapat dipercaya yaitu tentang transaksi yang bersifat keuangan untuk diperlukan dalam suatu kegiatan perusahaan dan penyusun laporan keuangan yang disampaikan untuk pengambilan keputusan yang tepat (Suwardjono, 2014 : 4).

Akuntansi Keuangan. Akuntansi keuangan adalah suatu proses dimana berujung pada penyajian dan mengkomunikasikan laporan keuangan suatu organisasi atau entitas dalam pengambilan keputusan bagi para pengguna informasi baik eksternal maupun internal (Giri, $2017: 4)$.

Aset Tetap. Hery (2014 : 121) menyatakan aset tetap (fixed assets) merupakan aset yang terlihat secara fisik dan memiliki sifat yang relatif permanen dan juga memiliki masa manfaat yang panjang. Aset tidak berwujud adalah aset yang tidak memiliki wujud atau tidak terlihat secara fisik yang merupakan hasil dari kontrak hukum, sosial, ekonomi dan lain-lain. Aset tetap dapat diperoleh dengan cara membeli secara tunai, membuat sendiri, pertukaran dan sebagainya.

Klasifikasi Aset Tetap. PSAK No. 16 paragraf 37 menyatakan bahwa dalam pengelompokannya, suatu kelas aset tetap dalam operasi entitas memiliki kesamaan sifat dan kegunaan. Berikut ini beberapa contoh kelas tersendiri yaitu meliputi tanah, bangunan, kendaraan, mesin, perabotan, peralatan kantor, kapal dan pesawat.

Depresiasi Aset Tetap. Sumarsan (2018 : 64) menyatakan depresiasi (penyusutan) merupakan alokasi secara sistematis jumlah yang dapat disusutkan dari suatu aset sepanjang masa manfaat. Dalam PSAK No. 17 menyatakan bahwa depresiasi dilakukan dengan berbagai metode yaitu:

a. Berdasarkan waktu : Metode garis lurus, Metode jumlah angka tahun, Metode saldo menurun, dan Metode saldo menurun ganda.

b. Berdasarkan penggunaannya : Metode waktu penggunaan, dan Metode kuantitas produksi.

Sewa. PSAK No. 30 paragraf 04 menyatakan bahwa ialah suatu perjanjian kontraktual dimana pihak lessor memberikan hak kepada pihak lessee dalam memakai barang modal dengan jangka waktu yang ditentukan. Untuk imbalannya, lessee melakukan serangkaian pembayaran kepada lessor.

Jenis-jenis sewa. berikut ini merupakan berbagai jenis sewa yang sering digunakan dalam aktivitas perusahaan adalah sebagai berikut :

1. Sewa Pembiayaan. Sewa pembiayaan merupakan perjanjian kontraktual antara lessor dan lessee dalam penggunaan suatu aset dalam waktu yang telah disepakati, dan memiliki hak opsi untuk membeli suatu aset pada akhir masa sewa. 
2. Sewa Operasi. Sewa operasi merupakan perjanjian antara lessor dan lessee yang pada akhir masa sewa tidak terjadi pengalihan kepemilikan atas aset sewaan dari lessor kepada lessee dimana aset sewaan tersebut harus dikembalikan.

\section{Sewa Pembiayaan oleh Lessee}

Pengakuan awal. Dalam sewa pembiayaan lessee mengakui aset sewa guna usaha dan liabilitas sewa guna usaha sebesar nilai wajar atau nilai kini dari pembayaran sewa minimum pada awal masa sewa dalam laporan posisi keuangan.

Jurnal untuk mencatat pengakuan awal dalam perjanjian sewa :

Aset Sewa

Utang Sewa
XXX

$\mathrm{XXX}$

Pengukuran Setelah Pengakuan Awal. Bagian yang merupakan beban keuangan dan pengurang liabilitas dipisahkan dalam pembayaran sewa minimum terhadap aset sewaan. Pada setiap periode akuntansi dalam sewa pembiayaan untuk aset tersusut menimbulkan beban penyusutan dan beban keuangan. Untuk penyusutan aset sewaan dalam kebijakannya untuk sewa pembiayaan konsisten terhadap aset milik sendiri dan dalam melakukan perhitungan penyusutan terhadap aset sewaan berdasarkan dengan PSAK No. 16 dan 19 tentang aset tetap dan aset tak berwujud.

Jurnal untuk mencatat pembayaran angsuran sewa :

\begin{tabular}{ll} 
Utang Sewa & xxx \\
Beban Pajak & xxx \\
Beban Bunga & xxx \\
\multicolumn{1}{c}{ Kas } &
\end{tabular}

Jurnal untuk mencatat penyusutan aset sewaan :

Beban Penyusutan

$\mathrm{XXX}$

Akumulasi penyusutan

XXX

Pengungkapan. Suatu aset yang disewagunausaha diungkapkan kedalam laporan posisi keuangan sebagai aset tetap dengan kelompok tersendiri dan kewajiban sewa disajikan terpisah dengan kewajiban lain. Berdasarkan PSAK No. 30 pengungkapan akuntansi sewa guna usaha dalam memenuhi kriteria PSAK No. 60 Instrumen Keuangan oleh lessee di dalamya diungkapkan hal-hal sewa pembiayaan mengenai total tercatat neto pada tanggal pelaporan untuk setiap kelompok aset, mengungkapkan nilai kini di setiap periode satu tahun, sampai lima tahun atau lebih dan total pembayaran sewa minimum masa depan di akhir pelaporan. Jumlah penerimaan pembayaran minimum dan kontrak sewa tidak dapat dibatalkan di akhir periode pelaporan serta rental kontinjen diakui sebagai beban.

\section{Sewa Operasi oleh Lessee}

Pengakuan awal. Selama masa sewa dalam sewa operasi, pembayaran sewa itu diakui sebagai beban dengan dasar garis lurus, apabila terdapat dasar lain yang lebih mencerminkan waktu dan manfaat dari pengguna aset.

Jurnal mencatat pengakuan awal :

Beban Sewa

Kas
XXX

$\mathrm{xxx}$

Pengungkapan. Menurut PSAK No. 30 dalam memenuhi kriteria untuk tambahan pengungkapan PSAK No. 60 tentang Instrumen Keuangan lessee mengungkapkan hal-hal berikut mengenai sewa operasi yaitu pembayaran sewa minimum dengan seluruh jumlahnya tidak dapat dibatalkan dalam waktu satu tahun, sampai lima tahun bahkan lebih dari lima tahun, untuk pembayaran sewa minimum dalam sewa operasi diakui sebagai beban dengan pengungkapan terpisah setip jumlah pembayaran sewa minimum. 


\section{METODE PENELITIAN}

Jenis Penelitian. Jenis penelitian yang digunakan dalam penelitian ini adalah kualitatif deskriptif.

Tempat dan Waktu Penelitian. Penelitian dilakukan pada PT. Bank SulutGo Kantor Pusat, yang beralamat di J1. Sam Ratulangi No. 9 Manado, Sulawesi Utara. Penelitian ini dimulai dari bulan Agustus 2018 - Oktober 2018.

\section{Jenis, Sumber dan Metode Pengumpulan data}

Jenis data. Jenis data yang digunakan dalam penelitian ini adalah data kuantitatif dan data kualitatif yang berupa data akuntansi dan hasil wawancara.

Sumber data. Sumber data yang digunakan dalam penelitian ini ialah data primer dan data sekunder. Data primer berupa data hasil wawancara yang dilakukan di PT. Bank SulutGo dan berupa profil, visi misi perusahaan dan data sekunder berupa daftar sewa aset tetap.

\section{Metode pengumpulan data}

1. Wawancara. Merupakan suatu tahapan dalam mendapatkan penjelasan informasiinformasi dengan cara melakukan proses tanya jawab secara langsung, ataupun tidak langsung melalui media telekomunikasi antara narasumber dan peneliti. Wawancara pada hakikatnya merupakan suatu kegiatan dalam memperoleh informasi-informasi tentang sebuah tema yang diangkat dalam penelitian secara mendalam. Adapun pertanyaanpertanyaan wawancara mengenai penelitian ini yaitu tentang penerapan akuntansi leasing atas perolehan aset tetap pada PT. Bank SulutGo adalah sebagai berikut:

1. Bagaimana prosedur kebijakan permintaan dan pengadaan sewa aset tetap di PT. Bank SulutGo?

2. Bagaimana kebijakan leasing di PT. Bank SulutGo?

3. Jenis aset tetap apa dan berapa yang diperoleh dengan cara sewa di PT. Bank SulutGo?

3. Bagaimana pengakuan awal sewa pembiayaan yang dilakukan oleh PT. Bank SulutGo?

4. Bagaimana pengukuran setelah pengakuan awal sewa pembiayaan yang dilakukan PT. Bank SulutGo yaitu tentang pembayaran sewa minimum dan penyusutan terhadap aset sewaan?

5. Bagaimana pengungkapan sewa pembiayaan dalam laporan keuangan di PT. Bank SulutGo?

6. Jika aset sewaan mengalami kerusakan pada masa sewa, bagaimana perlakuannya terhadap aset sewaan yang mengalami kerusakan?

2. Observasi. Observasi adalah suatu kegiatan dalam mengumpulkan informasi yang dibutuhkan dalam menyajikan suatu gambaran yang nyata dari kejadian untuk menjawab permasalahan penelitian, mengevaluasi yaitu mengukuran tentang aspek tertentu dan melakukan umpan balik terhadap pengukuran tersebut. Hasil dari observasi yaitu suatu kejadian, peristiwa, kondisi atau suasana tertentu, aktivitas.

3. Studi Dokumen. Studi dokumen ialah suatu proses pengumpulan data yang kualitatif dengan sejumlah fakta dan data yang tersimpan dalam bentuk dokumentasi. Sebagian besar data berbentuk dokumen perjanjian transaksi sewa, metode penyusutan, neraca dan lain lain sebagainya.

Metode Analisis. Metode analisis yang digunakan dalam penelitian ini adalah metode analisis deskriptif yaitu menguraikan, menggambarkan, membandingkan hasil penelitian dengan PSAK No. 30 dan menerangkan sesuai fakta, fenomena, dan keadaan yang terjadi saat penelitian berjalan dan menyuguhkan apa adanya. 


\section{HASIL PENELITIAN DAN PEMBAHASAN}

\subsection{Hasil Penelitian}

Kebijakan Leasing Pada PT. Bank SulutGo. Investasi yang dilakukan oleh PT. Bank SulutGo berpengaruh pada modal PT. Bank SulutGo itu sendiri, jadi yang bisa dibelanjakan sebagai capex atau biaya modal sebagai investasi sebesar 30\% dari modal PT. Bank SulutGo. Jika pengeluaran modal sudah mendekati atau sudah mencapai $30 \%$ yang merupakan ketentuan yang ditetapkan PT. Bank SulutGo, maka PT. Bank SulutGo tidak bisa lagi melakukan pembelian aset secara tunai, sehingga PT. Bank SulutGo mencari alternatif lain untuk mendapatkan suatu aset tetap yaitu dengan cara leasing atau sewa guna usaha.

Deskripsi Transaksi Sewa Aset Tetap oleh PT. Bank SulutGo. PT. Bank SulutGo melaksanakan perjanjian kontrak dengan PT. X dimana perjanjian kontrak tersebut berkaitan dengan transaksi sewa guna usaha aset tetap yaitu mesin ATM. Perjanjian antara PT. Bank SulutGo dengan PT. X terdapat beberapa PKS dengan aset sewa sebanyak 56 unit mesin ATM dimana 25 unit sudah menjadi aset tetap dan 31 unit masih dalam masa sewa. Berikut ini merupakan salah satu deskripsi transaksi sewa mesin ATM yang di peroleh dengan cara sewa dalam kontrak perjanjian antara PT. Bank SulutGo dengan PT. X tahun 2015. Perjanjian sewa mesin ATM dengan merk Diebold sebanyak 25 unit yang dilakukan oleh PT. Bank SulutGo dengan PT. X dikelompokkan sebagai capital lease (sewa pembiayaan) atau disebut oleh PT. Bank SulutGo yaitu sewa beli yang pada akhir masa sewa mengalihkan kepemilikan aset kepada PT. Bank SulutGo.

Total Harga Perolehan 25 Unit Mesin ATM

Masa Sewa

Angsuran Sewa Per bulan 25 Unit Mesin ATM
: Rp 6.781.860.000

: 3 tahun (36 bulan)

: Rp $\quad 171.250 .000$

Penerapan Akuntansi Sewa Untuk Sewa Pembiayaan Pada PT. Bank SulutGo. Adapun penerapan akuntansi leasing pada PT. Bank SulutGo adalah sebagai berikut.

a. Pengakuan. PT. Bank SulutGo pada awal perjanjian sewa tidak mengakui bahwa sewa pembiayaan sebagai aset dan liabilitas dalam laporan posisi keuangan.

b. Pengukuran. Pembayaran sewa oleh PT. Bank Sulutgo sebagai lessee dibayar dan dicatat oleh Divisi Umum bagian Departemen Pelayanan Umum. Jurnal yang dibuat oleh Departemen Pelayanan Umum yaitu:

D Sewa Mesin ATM

XXX

K Pihak Ketiga Penyedia Jasa Mesin ATM xxx

Jurnal yang dibuat PT. Bank SulutGo di atas adalah jurnal untuk mencatat pembayaran angsuran sewa per bulan. Selama masa sewa PT. Bank SulutGo tidak melakukan perhitungan penyusutan karena aset sewa statusnya belum diakui dan tidak berpengaruh pada nilai aset oleh PT. Bank SulutGo.

c. Pengungkapan. Pada PT. Bank SulutGo aset sewa yaitu mesin ATM Diebold tidak dicatat ke dalam neraca sebagai aset dan hutang dengan pos atau akun tersendiri yaitu aset sewa guna usaha dan liabilitas sewa guna usaha

\subsection{Pembahasan}

\section{Penerapan Akuntansi Leasing Pada PT. Bank SulutGo}

a. Pengakuan. Berdasarkan hasil penelitian bahwa pada PT. Bank SulutGo pada saat awal perjanjian sewa tidak mengakui sewa pembiayaan sebagai aset dan liabilitas dalam laporan posisi keuangan sedangkan berdasarkan PSAK No. 30 pada awal perjanjian sewa penyewa mengakui sewa pembiayaan sebagai aset dan liabilitas dalam laporan posisi keuangan. Jurnal untuk mencatat pengakuan awal sewa berdasarkan PSAK No. 30 sebagai berikut: 
Tabel 1. Jurnal pencatatan pengakuan awal sewa

\begin{tabular}{lccc}
\hline & Nama Akun & Debet & Kredit \\
\hline \multirow{2}{*}{ Aset Sewa } & & xxx & - \\
& Utang Sewa & - & xxx \\
\hline
\end{tabular}

Pada Tabel 1 menunjukan bahwa aset sewa berada pada sisi debet, sedangkan hutang sewa berada pada sisi kredit.

b. Pengukuran. Berdasarkan hasil penelitian terdahulu Yanti, R dan Hamdani, A (2013) pada saat pembayaran sewa yang dilakukan oleh perusahaan adalah dengan mencatat:

D Biaya Sewa Alat Berat

K Kas $\quad \mathrm{xxx}$

Pencatatan tersebut diatas sama halnya dengan hasil penelitian di PT. Bank SulutGo bahwa pada saat pembayaran angsuran sewa PT. Bank SulutGo mencatat :

D Sewa mesin ATM

K Pihak ketiga penyedia jasa mesin ATM

$\mathrm{XXX}$

Sedangkan berdasarkan PSAK No. 30 dipisah antara bagian yang merupakan beban keuangan dan pengurangan liabilitas. Jurnal yang seharusnya dicatat untuk pembayaran angsuran sewa berdasarkan PSAK No. 30 sebagai berikut:

Tabel 2. Jurnal pencatatan untuk pembayaran sewa

\begin{tabular}{lccc}
\hline & Nama Akun & Debet & Kredit \\
\hline Utang Sewa & & xxx & - \\
Beban Pajak & & xxx & - \\
Beban Bunga & Kas & xxx & - \\
& Kax & - & xxx \\
\hline
\end{tabular}

Pada Tabel 2 menunjukkan hutang sewa, beban pajak, beban bunga berada pada sisi debet, sedangkan kas berada pada sisi kredit. Hasil penelitian pada PT. Bank Sulutgo untuk aset sewa pembiayaan tidak melakukan pencatatan perhitungan penyusutan, Sedangkan berdasarkan PSAK No. 30 sewa pembiayaan menimbulkan beban penyusutan untuk aset tersusutkan dan beban keuangan pada setiap periode akuntansi dan kebijakan penyusutan untuk aset sewaan konsisten dengan aset yang dimiliki sendiri, dan perhitungan penyusutan yang diakui berdasarkan PSAK 16: Aset Tetap dan PSAK 19: Aset Tak Berwujud. Jurnal yang seharusnya dicatat oleh PT. Bank SulutGo untuk penyusutan aset sewa berdasarkan PSAK No. 16 sebagai berikut:

Tabel 3. Jurnal Pencatatan Penyusutan Aset Sewa

\begin{tabular}{ccc}
\hline Nama Akun & Debet & Kredit \\
\hline Beban Penyusutan & $\mathrm{xxx}$ & - \\
Akumulasi Penyusutan & - & $\mathrm{xxx}$ \\
\hline
\end{tabular}

Pada Tabel 3 menunjukkan beban penyusutan berada pada sisi debet, sedangkan akumulasi penyusutan berada pada sisi kredit.

c. Pengungkapan. Berdasarkan hasil penelitian bahwa pada PT. Bank SulutGo tidak mengungkapkan aset sewaan ke dalam neraca, dari hasil penelitian terdahulu Yanti, $\mathrm{R}$ dan Hamdani, A (2013) perusahaan juga tidak mencatat untuk sewa pembiayaan yaitu aset sewa guna usaha dan utang sewa guna usaha di dalam laporan posisi keuangan, sedangkan berdasarkan PSAK No. 30 aset sewa pembiayaan diungkapkan ke dalam neraca dengan kelompok tersendiri. Adapun laporan keuangan yang seharusnya diungkapkan pada akhir periode akuntansi oleh PT. Bank SulutGo sebagai berikut. 
Tabel 4. Pengungkapan Aset Sewa ke dalam Neraca

PT. Bank SulutGo

Neraca

Periode 31 Desember 2015

\begin{tabular}{|c|c|}
\hline Aktiva & Pasiva \\
\hline Aset Tetap: & Utang Jangka Panjang: \\
\hline Aset Sewa & Utang Sewa \\
\hline
\end{tabular}

Pada Tabel 4 menunjukkan aset sewa berada pada sisi aktiva, sedangkan hutang sewa berada pada sisi pasiva.

\section{KESIMPULAN DAN SARAN}

\subsection{Kesimpulan}

Berdasarkan hasil analisis dapat ditarik kesimpulan bahwa kegiatan sewa guna usaha dalam penerapan akuntansinya oleh PT. Bank SulutGo berdasarkan PSAK No. 30 sebagai standar acuan yang digunakan oleh PT. Bank SulutGo, secara keseluruhan hampir tidak sesuai dengan PSAK No. 30 untuk sewa pembiayaan. Hal ini dapat dilihat dari pengakuan, pengukuran dan pengungkapan, dimana pengakuan awal sewa oleh PT. Bank SulutGo tidak mengakui sewa pembiayaan sebagai aset dan liabilitas dalam laporan posisi keuangan sedangkan PSAK No.30 mengakui aset dan liabilitas dalam laporan posisi keuangan, pembayaran sewa tidak dipisahkan antara bagian yang merupakan beban keuangan dan pengurangan liabilitas, PT. Bank SulutGo juga tidak melakukan perhitungan penyusutan selama masa sewa sedangkan PSAK No. 30 pembayaran sewa dipisahkan antara bagian yang merupakan beban keuangan dan pengurangan liabilitas dan mencatat penyusutan terhadap aset sewa, PT. Bank SulutGo tidak mengungkapkan aset sewa dalam laporan keuangan sedangkan PSAK No. 30 diungkapkan ke dalam laporan keuangan dengan kelompok tersendiri.

\subsection{Saran}

Berdasarkan hasil penelitian yang telah dilakukan maka penulis memberikan saran mengenai penerapan akuntansi leasing terhadap perolehan aset tetap sesuai dengan standar keuangan yang berlaku sebagai berikut:

1. Pada saat pengakuan awal sewa, PT. Bank SulutGo seharusnya mengakui sewa pembiayaan sebagai aset dan liabilitas dalam laporan posisi keuangan.

2. Pada saat pembayaran sewa PT. Bank SulutGo seharusnya memisahkan antara bagian yang merupakan beban keuangan dan pengurangan liabilitas dan PT. Bank SulutGo juga seharusnya mencatat perhitungan penyusutan aset sewa sehinga pada laporan keuangan dapat diketahui nilai buku aset sewa tersebut.

3. PT. Bank SulutGo harus mengungkapkan aset sewa ke dalam laporan keuangan agar dapat dilihat keberadaan aset sewa dengan kelompok tersendiri.

4. Untuk perjanjian sewa yang baru nantinya, PT. Bank SulutGo harus mencatat transaksi sewa berdasarkan PSAK No. 30 tentang sewa guna usaha agar bisa terlihat di laporan posisi keuangan dengan kelompok tersendiri berdasarkan harga perolehan.

\section{DAFTAR PUSTAKA}

Bashi, N. dan Molla, F. 2013. The Future of Leasing Accounting. Journal of Applied Economics and Business. Volume 1. Issue 3. University of Shkodra "Luigj Gurakuqi”. Albania. 
Giri, E. F. 2017. Akuntansi Keuangan Menengah 1. Edisi 2. Cetakan Pertama. UPP STIM YKPN. Yogyakarta.

Hery. 2014. Akuntansi Aset, Liabilitas, dan Ekuitas. Grasindo. Jakarta.

Ikatan Akuntan Indonesia. 2014. Standar Akuntansi Keuangan. Selemba empat. Jakarta.

Pontoh, W. 2013. Akuntansi Konsep dan Analisis. Halaman Moeka. Jakarta Barat.

Sumarsan, T. 2018. Akuntansi Dasar dan Aplikasi Dalam Bisnis Versi IFRS. Edisi 2. Jilid 2. PT. Indeks. Jakarta.

Suwardjono. 2014. Akuntansi Pengantar Bagian 1 Proses Penciptaan Data Pendekatan Sistem. Edisi 3. Cetakan Ketujuh. BPFE-Yogyakarta.

Yanti, R. dan Hamdani, A. 2013. Analisis Akuntansi Leasing pada PT. Puri Green Resources Pekanbaru. Jurnal Akuntansi Keuangan dan Bisnis. Volume 6. Politeknik Caltex Riau. 